\title{
Scientific Trends and Role of Robots in the Agricultural Sector
}

\author{
E Mamatha, S Saritha \\ Department of Mathematics, GITAM University, Bangalore-561203 \\ Email: sricsrmax@gmail.com \\ Krishna Anand \\ Department of Computer Science, Sreenidhi Inst of Tech, Hyderabad \\ Email: skanand86@gmail.com \\ CS Reddy \\ Department of Mathematics, CIT - North Campus, Bangalore \\ Email: srisaimax@gmail.com
}

ABSTRACT-

The agriculture sector is essential to implement the automation technology to grow rapidly for better results and to produce crops for the requirement of the world population in the present scenario. Present existing technology and old mythologies and tools and types of machinery are not sufficient to achieve the targets. The enhanced technology and optimized energy utilization tools are straightaway to be adopted in the form of information technology machines that are more effective with old methods. The precision formation has revealed the advantages of machinery technology but needs to improve more for the next new equipment for the coming generations, which we call robotics technologies. The initiation of an autonomous system gives us a better prospect to build up a completely new variety of farming kits with the support of small elegant equipments like types of machinery which will do an accurate process, at the right time with the exact place, in the correct approach. A machine that contains an automatic control mechanism tracks the front running vehicle and follows, which has advantages of both vehicles that can be controlled and monitored effectively by a single driver in large farming sectors.

Keywords - Agriculture robots, automation, vehicle control, agricultural sector, vehicle monitoring.

\section{INTRODUCTION}

In the present generation, emerging countries do not have sufficient skilled human power in industrial fields particularly within the agricultural sector and consequently, this affects the expansion of developing countries [1, 2, 3]. Hence the earth possesses to seem towards automation of the sectors to reinforce the rate of growth and to beat the burning problems, especially in the food generation field. In any case, approximately $75 \%$ of people in India are enthusiastic about agriculture and the remaining is functioning in the commission sector. So we'd wish to review the agriculture sector and wish to enhance present existing tools for better yields in crops, qualitative and quantitative improvement. The innovative idea of our project is to automate the tactic of sowing crops like sunflower, baby corn, groundnut and vegetables like beans, lady's finger, pumpkin and pulses like black gram, mung, etc and to reduce the human effort. The automated plantation of seeds technology has is be administered by using robotic machines. At this, seed plantation is our day to day life is completed by a tractor in farms $[4,5]$. The normal method for seeding is that the manual one. The foremost requirement of Automation is to reduce manpower in the agriculture sector; the buzzword altogether industrial firms generally involve electrical, electronic component also as mechanical part. Automation saves plenty of tedious manual work and accelerates the assembly processes $[6,7,8]$. Now every day we have a lack of manpower. The energy required for this machine may be a smaller amount as compared with tractors or any agricultural instrument Pollution is additionally a huge problem that is eliminated by using a solar plate [9]. A manual farm consumes longer and leads to more pollution and is the true time to automate the cultivation process. Another is additionally need is to increase the high speed of operation.

The idea of robotic agriculture isn't a replacement idea and much of engineers have developed driverless machines within the past but they have not been successful as they did not have the facility to embrace the complexity of the important world [10]. The approach of treating crop and soil selectively according to their needs by small autonomous machines is that the natural next step within the event of Precision Farming (PF) because it reduces the world scale right down to the individual plant or Phytotechnology [11, 12]. Automatic sensing and control with on-the-go for each task is additionally important and much of research papers have shown that these systems are feasible but most are too slow, and hence not economically viable, to be operated on a manned tractor. Modern agriculture uses plenty of energy. It comes in many forms from fertilizers and chemicals to tractors and fuel. The Phytotechnology approach tries to specialize in the introduced energy to reinforce efficacy. Most of this machinery is extremely weather dependent [13]. Tractors 
cannot drive on the soil when it's wet, sprayers cannot add high winds, etc. Perhaps it'll be possible to develop smaller, less intrusive machinery which can allow more tasks to be administered in marginal conditions [14, 15]. This will allow the seeds to be planted when optimal for the crop and not be limited by the soil's ability to support the tractor.

Safety is another important factor. Any autonomous vehicle goes to travel wrong in a short time and thus the prospect of catastrophic failure should be minimized within the design process. Redundant, self-checking systems should be built into the system architecture to allow graceful degradation [16]. The vehicle should be in continual communication with rock bottom station, giving data about current conditions and contexts. This approach won't be economically justifiable in many broadacre crops but are going to be more attractive in high-value crops where a wise machine can replace expensive repetitive labor [17, 18]. If this approach were taken, the crop production cycle could be reduced to three stages: Seeding, Plant care, and selective harvesting.

\section{PRESENT TREND}

For many years robotic systems are widely used for industrial production and in warehouses, where a controlled environment is usually guaranteed. In agriculture and forestry, research into driverless vehicles has been a vision initiated within the first 1960s with basic research on projects on automatic steered systems and autonomous tractors [19]. Recently, the event of robotic systems in agriculture has experienced an increased interest, which has led many experts to explore the probabilities to develop more rational and adaptable vehicles supported a behavioral approach. A combined application of the newest sensor systems, communication technologies, positioning systems (GPS) and geographical information systems (GIS) have enabled researchers to develop new autonomous vehicles for top value crops within the agriculture and horticulture sector, also as for landscape management.

The robot's safety system would wish to be reliable enough for it to figure autonomously and unattended. It's relatively costly to develop safety systems if the vehicle possesses to be completely autonomous. In theory, they're going to work 24 hours every day but if a robot possesses to be attended then the time is restricted by the person Concepts are initiated to research if small autonomous machines would be more efficient to exchange the traditional large tractors [20]. These vehicles should be able to perform useful tasks all year round, unattended and prepared to behave sensibly during a semi-natural environment over long periods of some time. The small vehicles also can have less environmental impact replacing the over-application of chemicals and fertilizers, requiring lower usage of energy with better control matched to requirements, also as causing less soil compaction because of a lighter weight.

\section{ECONOMICS ASPECT}

The other factor which possesses to be considered is its cost then far, a few research scholars are published on the economic consequences by introducing autonomous field machinery to understand more sustainable production systems. Goense compared autonomous with conventional vehicles, equipped with implements having working widths from 50 to $120 \mathrm{~cm}$. He showed, if autonomous vehicles are often utilized 23 hours every day, it'd be economically feasible with slight reductions in prices of navigation systems or with slight increases parturient costs [21]. On the other hand, there could even be negative effects within the type of upper costs in traveling distances for service personal.

Additionally, Goi [22] analyzed the results of automation on machinery sizes and costs for soil tillage and crop establishment [23]. He assumed that the ratios between an autonomous tractor and a manned tractor, in terms of price, labor requirement and daily working hours would be 1.2, 0.2, and a few times, respectively. The analysis, including all direct machinery and timeliness costs, showed that the shift to automatic control would decrease the tractor size, implement sizes and implement investments to about half; decrease the tractor investment to about $60 \%$ and reduce the sum of annual tractor and machinery costs to approximately $65 \%$. Pedersen et. al. $[24,25]$ outlined a comparison between 3 different applications of robot systems with conventional systems for crop production and landscape treatment [26].

\section{POSSIBLE AUTOMATED FIELDS}

\subsection{Seedbed preparation}

Plowing is one of the foremost important primary cultivation processes and has been administered since the start of civilization. It's effectively the inversion or mixing of topsoil to arrange an appropriate seedbed. a little robot utilizing current technology doesn't have the energy density to sustain plowing over an outsized area because of the high levels of energy needed to cut and invert the dense soil. Secondly, the draft force required to plow also needs a relatively high weight to supply traction. The seed requires contact with the soil moisture to allow uptake of water and nutrients, it requires stability to hold the growing plant and a structure that allows the roots to develop and thus the shoots to grow.

\subsection{Seed mapping}

Seed mapping is that the concept of passively recording the geospatial position of each seed because it goes into rock bottom. It's relatively simple in practice as an RTK GPS is fitted to the seeder and infrared sensors mounted below the seed chute. Because the seed drops, it cuts the infrared beam and triggers a knowledge logger that records the position and orientation of the seeder. a simple kinematic model can then calculate the actual seed position. The seed coordinates can then be used to target subsequent plant-based operations. 


\begin{tabular}{|c|c|c|c|c|}
\hline $\begin{array}{l}\text { S. } \\
\text { no }\end{array}$ & Parameters & Manual & Vehicle & $\begin{array}{c}\text { Seed } \\
\text { Plantation } \\
\text { Process }\end{array}$ \\
\hline 1. & $\begin{array}{l}\text { Human } \\
\text { Power }\end{array}$ & $\begin{array}{l}\text { Needs } \\
\text { more } \\
\text { Power }\end{array}$ & $\begin{array}{c}\text { Has a } \\
\text { chance to } \\
\text { minimize }\end{array}$ & $\begin{array}{c}\text { Effective } \\
\text { Seed } \\
\text { Plantation }\end{array}$ \\
\hline 2. & $\begin{array}{c}\text { Time } \\
\text { Consumpt } \\
\text { ion }\end{array}$ & $\begin{array}{l}\text { Needs lot } \\
\text { of time }\end{array}$ & $\begin{array}{l}\text { Lot of } \\
\text { Time can } \\
\text { be saved }\end{array}$ & $\begin{array}{c}\text { Can } \\
\text { complete } \\
\text { the seed } \\
\text { Plantation }\end{array}$ \\
\hline 3. & $\begin{array}{c}\text { Sowing } \\
\text { Technique }\end{array}$ & $\begin{array}{c}\text { It's } \\
\text { works } \\
\text { Manually } \\
\end{array}$ & $\begin{array}{c}\text { Same like } \\
\text { manual }\end{array}$ & $\begin{array}{l}\text { Mechanicall } \\
\text { y processed }\end{array}$ \\
\hline 4. & $\begin{array}{c}\text { Between } \\
\text { the Seeds } \\
\text { space }\end{array}$ & $\begin{array}{c}\text { Not } \\
\text { possible } \\
\text { to fix it }\end{array}$ & $\begin{array}{c}\text { Not } \\
\text { possible } \\
\text { like manual }\end{array}$ & $\begin{array}{l}\text { Can set up } \\
\text { the gap } \\
\text { between } \\
\text { seeds }\end{array}$ \\
\hline 5. & $\begin{array}{l}\text { Wastage } \\
\text { of Seed }\end{array}$ & $\begin{array}{l}\text { Nominal } \\
\text { wastage }\end{array}$ & $\begin{array}{c}\text { More } \\
\text { wastage }\end{array}$ & $\begin{array}{c}\text { Less } \\
\text { wastage }\end{array}$ \\
\hline 6. & $\begin{array}{c}\text { Energy } \\
\text { requireme } \\
\text { nts }\end{array}$ & $\begin{array}{l}\text { High } \\
\text { energy } \\
\text { required }\end{array}$ & $\begin{array}{l}\text { Very High } \\
\text { energy } \\
\text { needed }\end{array}$ & $\begin{array}{c}\text { For Seed } \\
\text { Plantation } \\
\text { less energy } \\
\text { needed }\end{array}$ \\
\hline 7. & $\begin{array}{l}\text { Pollution } \\
\text { problems }\end{array}$ & $\begin{array}{l}\text { Negligible } \\
\text { pollution } \\
\text { with } \\
\text { human }\end{array}$ & $\begin{array}{c}\text { More } \\
\text { Pollution } \\
\text { with } \\
\text { Vehicles }\end{array}$ & $\begin{array}{c}\text { No } \\
\text { Pollution }\end{array}$ \\
\hline 8. & $\begin{array}{c}\text { Alarm and } \\
\text { Display }\end{array}$ & $\begin{array}{c}\text { Not } \\
\text { possible } \\
\text { with } \\
\text { human } \\
\text { beings }\end{array}$ & $\begin{array}{c}\text { Not } \\
\text { possible }\end{array}$ & $\begin{array}{c}\text { Can arrange } \\
\text { Alarm and } \\
\text { display }\end{array}$ \\
\hline
\end{tabular}

\subsection{Seed placement}

Rather than just record the position of each seed it'd be better to be able to control the seed position. this is often ready to allow not only allow the spatial variance of seed density to be changed but even have the facility to vary the seeding pattern. Most seeds are dropped at high densities within each row, whilst having relatively more room between the rows. From first agronomic principles, each plant should have equal access to spatial resources of air, light, ground moisture, etc. Perhaps a hexagonal or triangular seeding pattern might be more efficient during this context. If suitable controls are fitted to allow synchronization between passes, then there's the likelihood to plant seeds on a daily grid which can allow orthogonal inter-row weeding. Tests of such a machine are getting to be administered at KVL in 2005.

\subsection{Reseeding}

Reseeding is that the concept of having the ability to spot where a seed wasn't planted, or that a crop plant has not emerged and a machine can automatically place another seed within the same position. this idea might be extended to transplanting a seedling rather than a seed if the encompassing plants are too far advanced. A reseeder would have the power to insert individual seeds/plants without disturbing the encompassing crop. Conventional seeders couldn't then be used as they create continuous slots within the soil. A punch planter might be developed to satisfy this role, or better still adapt a Japanese transplanter to affect one seedling at a time. Prior local micro-cultivation might be achieved by employing a targeted water jet (or gel) to pierce the soil and soften it ready for the seedling roots. Figure 1, shows a transplanter adapted to require a seeding mat. The seeding mat also can include crop nutrients. If this idea became efficient enough, it could also become the most seeder.

\subsection{Crop scouting}

One of the foremost operations within good management is the ability to collect timely and accurate information. Quantified data has attended to be expensive and sampling costs can quickly outweigh the benefits of spatially variable management. Data collection would be less expensive and timelier if an automatic system could remain within the crop carrying a spread of sensors to assess crop health and standing. A high clearance platform is required to carry instruments above the crop canopy and utilize GPS. Smaller sub-canopy machines are developed in student competitions.

\subsection{Weed mapping}

Weed mapping may be a process of recording the position and preferably the density of varied weed species using aspects of machine vision. One method is to only record the increased leaf area found in weedy areas as weeds are patchy and thus the crops are planted in rows. Another more accurate method is to use active shape recognition, originally developed to acknowledge human faces, to classify weed species within the sort of their outline. Current research has shown that up to 19 species are often recognized during this manner. The last word result's a weed map which can be further interpreted into a treatment map.

\subsection{Robotic welding}

Knowing the position and severity of the weeds many methods will kill, remove or retard these unwanted plants Different physical methods are often used that believe physical interaction with the weeds. A classic example is to interrupt the soil and root interface by tillage and promote the wilting of the weed plants. this may be achieved within the inter-row area easily by using classical spring or duck foot tines. Intra row weeding is harder because it requires the position of the crop plant to be known so that the highest effectors are often steered away. Within the close-to-crop area, tillage cannot be used as any disturbance to the soil is perhaps getting to wreck the interface between the crop and thus the soil. Non-contact methods are being developed like laser treatments and micro-spraying.

\section{VEHICLE MONITORING SYSTEM}

Multiple autonomous vehicles can improve the efficiency of agricultural operations by performing labor-intensive tasks like transporting, plowing, sowing, fertilizing, 
spraying, and harvesting. The simultaneous control of multiple robotic vehicles has received attention from several researchers. the follower vehicle must continually update its relative position concerning the leader to satisfy the tracking task. Regarding safety, absolute sensors like those employing GPS aren't suitable for the tracking task because they'll lose the satellite signal and are subject to multipath interference. Local sensors, like cameras and laser range finders (LRF), are considered to be better approaches and are successfully applied for tracking under both indoor and outdoor conditions. For tracking control of multiple robotic vehicles [7, 8, 9], a camera visionbased leader-follower relative position estimating method has been designed, recognizing a pacesetter vehicle using features of the leader vehicle.

In this section, a navigation system is supposed to manage a devotee vehicle with a person's running leader vehicle. The follower vehicle automatically tracks and monitored by the leader vehicle. Using this system, at a time two vehicles are often efficiently utilized in agricultural operations by one human driver. The tracking system is developed for the next vehicle and monitoring vehicle, and control of the follower is executed with the help of a camera-based system [11]. A stable and accurate monocular vision-based sensing system was designed, consisting of a camera and rectangular markers. A feedback control algorithm was used to allow the follower vehicle to trace the trajectory of the leader vehicle.

As described within the above figure, the relative position between the leader and follower. By identifying the relative heading angle, relative distance $\mathrm{D}$, and orientation angle of the leader relative to the follower, the follower vehicle could identify the leader position. The leaderfollower relative position was obtained from the cameramarker system, during which the camera was mounted on the rear wheel canter point relative heading angle b, relative distance $\mathrm{D}$, and orientation angle of the leader relative to the follower. Figure of the follower vehicle, the marker was installed perpendicular to the middle line of the leader vehicle and thus the position of the center square of the marker was at the rear wheel center point of the follower vehicle, the marker was installed perpendicular to the middle line of the leader vehicle and thus the position of the center square of the marker was at the rear wheel center point $P$. The side length of each square $\mathrm{H}$ and thus the interval between square centers $\mathrm{L}$.

Utilizing the geometric relationship between similar triangles under a perspective model (Figure center PC in camera-based coordinates could be estimated as follows:

$$
\begin{aligned}
& X_{c}=\left(x-c_{x} / f_{x}\right) Z_{c} \text { where } Z_{c}=(H / h) f \\
& \text { and angel } \alpha=\tan ^{-1}\left(X_{c} / Z_{c}\right)
\end{aligned}
$$

Camera coordinates can be computed with geometrical property using triangular similarities in a perspective model as:

$$
\left[\begin{array}{c}
x_{c l} \\
y_{c l} \\
\theta_{c l} \\
1
\end{array}\right]=\left[\begin{array}{cccc}
\cos \beta & \sin \phi & 0 & l_{c} \cos \beta \\
-\sin \beta & \cos \beta & 0 & -l_{c} \sin \beta \\
0 & 0 & 1 & 0 \\
0 & 0 & 0 & 1
\end{array}\right]\left[\begin{array}{c}
x_{l F} \\
y_{l F} \\
\theta_{l F} \\
1
\end{array}\right]
$$

Where $p_{c}\left(x_{c}, y_{c}, z_{c}\right)$ and $P_{C}\left(X_{C}, Y_{C}, Z_{C}\right)$ image coordinate and camera coordinate systems respectively and $f, f x$ are focal length, $h$ is that the peak of squares within the image plane. The relative position between the follower and leader vehicles corresponds to $\mathrm{XZ}$ frame of reference and therefore the origin of the square is on the extent. The equation of the relative marker position concerning the control point is usually expressed.

In this research driverless follower place the most roles and also the Kalman filter which helps us in removing disturbance, which confirmed the high accuracy in following the human-driven leader and thus the performance of the system. The traveling courses are chosen according to standard agriculture operations, like straight, turning and zigzag paths. The results are satisfactory level. The accuracy of the maker was crosschecked both under dynamic and static conditions with the help of LRF.

\section{CONClusion}

In this study, a scientific approach that needs to be adopted in the agricultural and farming system is addressed and the role of robots and its importance in this sector. For superior and efficient yielding in agriculture production with optimal manpower automated machines provide a robust solution. Various controlling and automated systems for different works in the farming sector is discussed that works with monitoring machines With the support of a low-cost camera surveillance system, a remotely monitored camera, encoder, and servomotor, was employed. For the following vehicle, a tracking system with a steady speed and suitable steering position with a high accuracy system was established. A system was established for follower vehicles to the leading vehicle with low-cost reliable navigation to track the system.

\section{ACKNOWLEDGEMENTS}

Authors are thankful to editor and anonymous referrers for their valuable suggestions for the improvement of the paper.

\section{REFERENCES}

[1] Lenain, Roland, et al. "High accuracy path tracking for vehicles in presence of sliding: Application to farm vehicle automatic guidance for agricultural tasks." Autonomous robots 21.1 (2006): 79-97.

[2] Mamatha, E., Reddy, C. S., \& Sharma, R. (2018). Effects of viscosity variation and thermal effects in squeeze films. In Annales de Chimie. Science des Materiaux (Vol. 42, No. 1, p. 57-74). Lavoisier. 
[3] Pota, H., Eaton, R., Katupitiya, J., \& Pathirana, S. D. (2007, August). Agricultural robotics: A streamlined approach to realization of autonomous farming. In 2007 International Conference on Industrial and Information Systems (pp. 85-90). IEEE.

[4] Mamatha, E., Reddy, C. S., \& Prasad, K. R. (2016). Antialiased Digital Pixel Plotting for Raster Scan Lines Using Area Evaluation. In Emerging Research in Computing, Information, Communication, and Applications (pp. 461-468). Springer, Singapore.

[5] Liu, Chengliang, Mingjun Wang, \& Jun Zhou. "Coordinating control for an agricultural vehicle with individual wheel speeds and steering angles [Applications of Control]." IEEE control systems 28.5 (2008): 21-24.

[6] Mamatha, E., Reddy, C. S., \& Anand, S. K. (2016). Focal point computation and homogeneous geometrical transformation for linear curves. Perspectives in Science, 8, p. 19-21.

[7] Pedersen, Søren Marcus, S. Fountas, and S. Blackmore. "Agricultural robots-Applications and economic perspectives." Service robot applications. I-Tech Education and Publishing KG, 2008.

[8] Reddy, P. S., Rao, D. P., Mamatha, E., \& Srinivas, G. (2010). Finite Element Analysis of ThermoDiffusion and Diffusion-Thermo Effects on Convective Heat and Mass Transfer Flow Through a Porous Medium in Cylindrical Annulus in the Presence of Constant Heat Source. International journal of applied mathematics and mechanics, 6(7), 43-62.

[9] Sistler, F. "Robotics and intelligent machines in agriculture." IEEE Journal on Robotics and Automation 3.1 (1987): 3-6.

[10] Mamatha, E., Reddy, C. S., \& Prasad, R. (2012). Mathematical Modeling of Markovian Queuing Network with Repairs, Breakdown and fixed Buffer. i-Manager's Journal on Software Engineering, 6(3), 21.

[11] Asafe, Y. N., Bolaji, A. T., \& Amos, A. O. (2018). Spreading Trade Union Activities through Cyberspace: A Case Study. International Journal of Advanced Networking and Applications, 10(1), 3692-3697.

[12] Zhang, L., Ahamed, T., Zhang, Y., Gao, P., \& Takigawa, T. (2016). Vision-based leader vehicle trajectory tracking for multiple agricultural vehicles. Sensors, 16(4), 578.

[13] Elliriki, M., Reddy, C., \& Anand, K. (2019). An Efficient Line Clipping Algorithm in 2D Space. International Arab Journal of Information Technology, 16(5), 798-807.

[14] Espinosa, Felipe, et al. "Odometry and laser scanner fusion based on a discrete extended Kalman filter for robotic platooning guidance." Sensors11.9 (2011): 8339-8357.

[15] Reddy, C. S., Janani, B., Narayanan, S., \& Mamatha, E. (2016). Obtaining Description for Simple Images using Surface Realization Techniques and Natural Language Processing. Indian Journal of Science and Technology, 9(22), 1-7.

[16] Zhang, Xi, et al. "A semi-autonomous tractor in an intelligent master-slave vehicle system." Intelligent Service Robotics 3.4 (2010): 263-269.

[17] Kumar, M. S., Mamatha, E., Reddy, C. S., Mukesh, V., \& Reddy, R. D. (2017, September). Data hiding with dual based reversible image using sudoku technique. In 2017 International Conference on Advances in Computing, Communications, and Informatics (ICACCI) (pp. 2166-2172). IEEE.

[18] Periyasamy, P. (2019). H. 264/MPEG-4 AVC Video Streaming Analysis of AODV, OLSR and ZRP in MANET. International Journal of Advanced Networking and Applications, 10(6), 4076-4082.

[19] Mamatha, E., Sasritha, S., \& Reddy, C. S. (2017). Expert System and Heuristics Algorithm for Cloud Resource Scheduling. Romanian Statistical Review, 65(1), 3-18.

[20] SoleimaniRoozbahani, F., ShojaeiBarjouei, R., \& Hojjati, S. N. (2018). Identifying an appropriate model for information systems integration in the oil and gas industry. International Journal of Advanced Networking and Applications, 10(1), 3687-3691.

[21] Anand, K., Mamatha, E., Reddy, C.S., Prabha, M. (2019). Design of neural network based expert system for automated lime kiln system. Journal Européen des Systèmes Automatisés, Vol. 52, No. 4, pp. 369-376.

[22] Goi, Hien K., et al. "Vision-based autonomous convoying with constant time delay." Journal of Field Robotics 27.4 (2010): 430-449.

[23] Mamatha, E., Saritha, S., \& Reddy, C. S. (2016). Stochastic Scheduling Algorithm for Distributed Cloud Networks using Heuristic Approach. International Journal of Advanced Networking and Applications, 8(1), 3009.

[24] Bala, M., \& Kumar, M. (2019). An Energy-Efficient routing protocol based on TABU-Genetic Strategy in Wireless Sensor Network. International Journal of Advanced Networking and Applications, 10(6), 4099-4104.

[25] Reddy, C., \& Prasad, K. R. (2010). The Study State Analysis of Tandem Queue with Blocking and Feedback. International Journal of Advanced Networking and Applications, 1(1), 45-51.

[26] Prakash, K., et. al.,. (2017). A study of image processing in agriculture. International Journal of Advanced Networking and Applications, 9(1), 3311. 